\title{
Diagnosis of Occupational Asthma in Flour Mills at South Cairo
}

\section{Mohamed Saied El Gewily ${ }^{1}$, Moustafa El Husseini ${ }^{1}$, Safia Beshir ${ }^{2}$, Safaa $_{\text {Elserougy }}{ }^{2}$, Salwa F Hafez ${ }^{2}$, Mohamed S El Hamshary ${ }^{2}$}

${ }^{1}$ Faculty of Medicine, Ain Shams University; ${ }^{2}$ National Research Centre

Received:December 2016Accepted : March 2017

\section{Abstract}

Introduction: Occupational asthma is an international problem affecting largenumber of workers. Few studies were done on occupational asthma in Egypt focusing mainly on asthma symptoms and not on spirometric tests.Objective: The present study investigated the presence of occupational asthma (BA) among workers at flour mills of south Cairo as there was a lack of data. Methods: The participants $(n=120)$ were recruited from flour mills at South Cairo. A questionnaire, clinical examination, chest x-ray,spirometry, bronchodilator test andpeak flow rate variabilitytest were done. Occupational asthma was diagnosed according to GINA guidelines. Results: This study showed that $25 \%$ of mills workers had asthma related to work.The asthma symptoms appearduring work which showed improvement after leaving workplace. It showed also reversibility in FEV1,PEFR as well as diurnal PEFR variability characteristics of occupational asthma. It revealed also that asthmatic workers had lower level of spirometric parameters in relation to non-asthmatic. Conclusion: Asthma questionnaire followed by ventilatory function test assessing reversibility and variability can be used for early diagnosis of occupational asthma in Egypt.

Keywords: bronchialreversibility andvariability; Flour dusts; Bronchodilator test; occupational asthma

Corresponding author,Mohamed El HamsharyEmail :mohmd_soliman@yahoo.com

\section{Introduction:}

Bronchial asthma is a an important widely spreadpublic health problem affecting around 300 million persons all over the world with high degree of mortality and morbidity ${ }^{1)}$.All countries whatever their socioeconomic states are suffering. Asthma affects people at all age group. When it is uncontrolled it can place severe limits on daily life and is sometimes fatal. ${ }^{2}$

It was found that host factors and environmental factors play a role in asthma developmentHost factors are: genetic predisposition to atopy, obesity and sex while environmental factors include: allergens either indoor or outdoor, infections, tobacco smoke, air pollution and occupational sensitizers. ${ }^{3}$

Bronchial Asthma is characterized by a two or more of the following symptoms: wheeze, cough,shortness of breath and chest tightness. These symptoms worse at late night or in the early morning as well asvary over time and in intensity .They are also triggered by viral infections (colds), exercise, allergen exposure, changes in weather, laughteror irritants such as car exhaust fumes, smoke or strong smells ${ }^{4}$

The beginning of the following respiratory symptoms since childhood as well as past history of allergic rhinitis or eczema, or a family history of asthma or allergy, 
increases the possibility of bronchial asthma ${ }^{5}$ Physical examination in asthmatics is usually normal. Expiratory wheezing (rhonchi) is the most frequent abnormality heard by stethoscope.,

Pulmonary function tests are used to confirm asthma diagnosis and assessing its severity Lung Function varies in magnitudeover time to a greater extent than in Healthy populations. It ranging from normal to severe reduced levels according to asthma severity. this variability is more seen in poorly controlled asthma. ${ }^{6}$

Occupational sensitizers is considered one of the commonest environmental agents causing occupational asthma affecting around $10 \%$ of working adults in the worldNicholson et al.2005) $)^{15}$ It is a special type of Bronchial asthma defined as "variable airway obstruction causally related to the exposure to a specific compound in the workplace".(GINA.2011) ${ }^{2}$ The diagnosis of $\mathrm{OA}$ requires a defined history of occupational exposure to an established or suspected sensitizing agents in the workplace in occupational asthma, a latent period of at least one year should be present between the beginning of work and the appearance of asthma symptoms. Aclear relationship should be present betweenasthma symptoms and the workplace in the form of: appearance of asthma symptoms at work or early night after returning home. It worsens at early night before sleep and improve or disappear completely at late night or early morning on awakening. OA shows diurnal improvement of symptoms in contradictory to the ordinary bronchial asthma.Also there isimprovement of asthma away from work in the weekend and holidays and worsening of symptoms on returning to work showing weekly variability. $^{7}$ Physical examination is usuallynormal like bronchial asthma so we refer to spirometry to confirm the diagnosis especially reversibility and variability tests. ${ }^{4}$

Occupational asthma is common among in two mills workers due to exposure toorganic dust full of allergens either from the grain components itself or from contaminants likeinsects, bacteria, endotoxins, molds, fungi, mites. ${ }^{8}$ The aim of the study is toexplore the prevalence of occupational asthma among flour mills at south Cairo asthere is no available data of confirmed diagnosis using bronchodilator and variability test.

\section{Methods}

Study design and poulation:The study was conducted as across-sectional study in two mills at South Cairo ((El-Sherouk and ElTebbin). Both mills were aside. All workers in both mills were recruited $(n=120)$ at the outpatient clinic of both mills. The workers were all males from different departments (grinding, packing, storage and garbling).

The study includes a questionnaire, clinical examination, chest x-ray and spirometry. An interview questionnaire: Asthma and respiratory symptoms, Chest examination for rhonchi, breath soundintensity and any other findings, chest X-ray were obtained from the records of the workers at the mills to exclude other chest diseases. Spirometry was done for all participants using portable spirometer (Mir spirolab 2) according to GINA guidelines $2011^{2}$, 2014. Participants were asked to perform forced expiratory maneuver where three reproducible curves were obtained $( \pm 5 \%)$.the spirometry was done from 8-11 am.The measured parameters included forced vital capacity(FVC),forced Expiratory volume in 1 second( FEV1), forced expiratory volume Ratio (FEV1\%) and peak Expiratory flow rate(PEFR).

Bronchodilator test: The test was done for all participants regardless of asthma 
history or initial spirometric values. Each participant was given salbutamol inhalation buff at a dose of $400 \mu \mathrm{g}$ and left for 15 minutes. Then a post-bronchodilator spirometric measurement was done for the participants. An improvement in percent predicted FEV1 (pp FEV1) after bronchodilator inhalation >12 GINA.,2011²and GINA 2014) ${ }^{4}$ or in PEFR percent predicted (pp PEFR) $\geq 20 \%$ $\left(\right.$ GINA,2011) ${ }^{2}$ is considered bronchial reversibility which confirm the diagnosis of bronchial asthma if present.

PEFR Variability test: The test was done for all participantsat the outpatient clinic regardless of asthma history or initial spirometric values. The nocturnal PEFR was performed after 12 hours from the previous spirometrictests(from 8-11pm).. the difference between the diurnal and nocturnal (pp PEFR) was also calculated to measure PEFR Variability. A drop in the nocturnal(ppPEFR ) greater than $20 \%$ in a symptomatic person as well as with a positive bronchial reversibility is considered occupational asthma.

Statistics: Age, Body Mass Index,smokingindex, duration of exposure length of employment and spirometric parameters, are expressed as mean $\pm \mathrm{SD}$,minimum, maximum. Comparison betweenthe pulmonary functions has been performed by means of McNemar test for categorical and continuous variables respectively. A $\mathrm{p}$ value lower than 0.05 was considered as statistically significant

Ethical consideration: Approval of the study protocol was obtained from the Ethical committee at the faculty of Medicine, Ain Shams University. Informed consent was obtained from each participant before enrolment and after explanation of the study objectives

\section{Results}

Table(1) shows that the mean age of the participants was 49 \pm 5.6 [37-59] years with mean duration of exposure 27.4 \pm 5.1 [20-40] years. Smoking was found in $61.7 \%$ of the workers. Table (2)shows the Clinical findings among participant workers which were in the form of: (28.3\%) of them had recurrent RTI and asthma symptoms related to triggers (25.8\%) like cold, irritants, laugh, and work. These symptoms resolve completely after awaking in 24(20.0\%) and partially in $6(5.0 \%)$.Most of the asthma symptoms were in the form of Episodic chest tightness $(25.8 \%)$,Episodic

cough28(23.3\%)and Episodic dyspnea27(22.5\%). This table shows also that small number of workers suffer from Chronic dyspnea (11.7\%) and cough (5.8\%). (8.1\%) persons had abnormal chest examination and $\mathrm{x}$ ray characteristics of COPD. Table (3) shows the \% pred FVC was impaired in $41(34.2 \%)$ of the workers. After administration of bronchodilator the \% pred FVC became normal in all workers.

The $\%$ pred FEV1 was impaired in 75 $(62.5 \%)$. the frequency of post bronchodilator was significantly decreased (35 (29.2\%), $\mathrm{p}<0.001)$ meaning that 40 workers out $75(53.3 \%)$ improved on bronchodilator. The $\%$ pred FEV1 change after bronchodilator was $>12 \%$ in 45 out of the 75 workers with Pre-BD impaired FEV1 $\left(x^{2}=25.7, p<0.001\right)$ which means that 45 workers having positive FEV1 reversibility. The frequency of $\%$ pred FEV1/FVC $<85 \%$ was $102(85.0 \%)$ among all participants. The latter frequency increased to $115(95.8 \%)$ after bronchodilator.

The $\%$ pred PEFR was impaired in 67 $(55.8 \%)$. the frequency of impaired \% pred PEFR was significantly lowered(16 (13.3\%), $\mathrm{p}=0.000)$ meaning that 51 workers out of 67(76\%) improved on bronchodilator. The $\%$ pred PEFR change after bronchdilator was $\geq 20 \%$ in $44(36.7 \%)$ out of 67 workers with Pre-BD 
impaired PEFR $\left(x^{2}=25.7, p<0.001\right)$ which means that 44 workers having positive PEFR reversibility. Table(4) shows that Late PEFR among participants at wheat mills of south Cairo is lower than Early PEFR(5.8 \pm 2.4

[0-10.83] versus7.0 $\pm 1.2[4.4-9.7]$ ) with a diurnal variability in the PEFR greater than $20 \%$ (21.0 \pm 6.8 [10.0-46.0]) which indicate occupational asthma.

Figure (1)shows that $25 \%$ of mills workers suffer from occupational asthma.

\section{Discussion}

Occupational asthma is an international problem affecting $10 \%$ of the working adults. ${ }^{15}$ Few studies were done on occupational asthma in Egypt focusing mainly on asthma symptoms. In this study awell designed questionnaire according to the last GINA guidelines $2014^{9}$ as well as ventilatory functions tests focusing on bronchial reversibility and variability were done to workers of Helwan flour mills.

The current study reported that Many participant workers had recurrent RTI (28.3\%) and asthma symptoms related to triggers (25.8\%) mainly work which significantly resolved after awaking and improve at the end of work day as well as in the weekend.

This agrees with Tarlo et al. 20097) Who reported that these features are typical of occupational asthma this is because the exposure to allergen is mainly at work so the symptoms appear during work, improve at the end of the day and resolve on awaking. the symptoms also improve in the weekend due to absence of allergen exposure. Nowadays These clinical characteristics became the diagnostics criteria stated by the GINA guidelines $2014^{9}$.

This study showed that significant numbers of asthmatics were normal on chest examination as well as chest $\mathrm{x}$ ray .This is in agreement with Nicholson et al.
$2005^{5}$ \&Levy et al.2009 ${ }^{4}$ who observed that the physical and radiological examination of the respiratory system of asthmatics were usually normal because asthma is associated by reversible variable airways obstruction.

This study showed also a significant improvement in the workers spirometric parameters: FVC,FEV1,FEV1/FVC,PEFR after bronchodilator administration .These findings are in accordance with Brouwer et al.2008 ${ }^{10}$;Levy et al.2009 ${ }^{4}$ andQuanjer et al.2012 ${ }^{11}$ who prove that asthma is characterized by variable airflow limitation in all spirometric parameters.

This study revealed reversibility in 45 workers by FEV1 reversibility test while 44 by PEFR reversibility test which is in agreement withBrouwer et al., $2008^{10}$; Reddel et al.2009 ${ }^{12}$ and Tan et al., $2012^{13}$ who reported that reversibility in ventilatory lung function is an Essential component of the diagnosis of asthma. Nowadays the GINA takes this diagnostic point in consideration in subjects with symptoms doubtful of asthma not in asymptomatic persons.

Reddel et al, 2009 ${ }^{12}$ and Quanjer et al., $2012^{11}$ prove that Forced expiratory volume in 1 second Reversibility (FEV1) is more reliable than that of peak expiratory flow (PEF) which agree with our results. Nowadays GINA guidelines $2014^{9}$ prefer FEV1 reversibility more than that of PEFR.In fact, we found thirty subjects out of 120 male workers suffering from occupational asthma representing around $25 \%$ of the workforce.

The current study doesn't agree with western studies approved by GINA like that of Culinan et al.,1994 ${ }^{14}$ who showed that the prevalence of occupational asthma among flour mills workers not exceed 14\%.Another study done by Talini et al.,2002 $2^{15}$ found that the prevalence of occupational asthma among flour mills 
workers became $10 \%$ due improvement of industrial hygiene.

The prevalence of occupational asthma among flour mills is low in western countries in comparison to our country. This may be attributed to the improvement in industrial hygiene as well as low level of growth of microorganisms causing asthma due to cold dry climate. The current study doesn't also agree with Eastern studies done in Asia and Africa. Like that of Ijadunola et al.,2004 ${ }^{16}$ whoreported that the prevalence of occupational asthma among flour mills workers in Ibadan Governorate, Nigeria was 54\%.Another study done by Narjis et al.,2007 20 found that the prevalence of occupational asthma among flour mills workers of Basrah Governorate, Iraq was $45 \%$.

The prevalence of occupational asthma among flour mills is high in Eastern countries in comparison to our country. This may be attributed to high level of growth of microorganisms causing asthma due to hot humid climate.

This studyisn't in accordance with a previous Egyptian study done by Gaafar et al. $1988^{18}$ who found that the prevalence of occupational asthma among flour mills workers in Menoufia Governorate was 13\%. This may be attributed toincrease both temperature and humidity in Helwan in comparison to menoufia as well as global warming occurring in recent years allowing further growth of microorganisms as a result of climatic changes.

\section{Conclusion}

From This study we concluded that the diagnosis of occupational asthma in workers previously undiagnosed can be performed by a well designed questionnaire focusing on asthma symptoms, its improvement, worsening , relation to triggers mainly work, Followed by pulmonary function tests to assess bronchial reversibility and variability. We concluded also the importance of industrial hygiene measures in prevention as well early detection and treatment of susceptible workers.

\section{References}

1. Neffen H,Fritscher C,Schacht F .Astma control in Latin America (AIRLA) survey. Rev PanamSalud Publica.2005;17(3):191197

2. GINA Report . Global strategy for asthma management and prevention. 2011( 1 ): 16

3. Busse W, LemanskeR .Asthma .N Eng J Med.2001;344(50):350-362

4. Levy M, Quanjer P, Booker R.Diagnosticspirometry in primary care:. Prim Care Respir J.2009; (18):130-147

5. Nicholson P,Cullinan P,Taylor A .Evidence based guidelines for the management of occupational asthma.Occup Environ

Med:.2005;62(5):290-299

6. Reddel H, Ware S, Marks G, Salome C, Jenkins C, WoolcockA.Differences between asthma exacerbations and poor asthma control . Lancet 1999;(353):364369

7. Tarlo S, Malo J. asthma in the workplace. Proc Am ThoracSoc.2009;(5):339-349.

8. 8-Baur $X$, Sigsgaard $T$, Aasen $T$. Guidelines for the management of workrelated asthma. EurRespir J .2012;(39):529-545

9. GINA Report . Global strategy for asthma management and prevention. 2014( 1) : 2

10. Brouwer A, Brand P.Asthma education and monitoring, what has been shown to work.PaediatrRespir Rev.2009; (9):193-199

11. Quanjer P, Stanojevic S, Cole T. Multi-ethnic reference values for Pulmonary function equations. EurRespir J .2012;(40):1324-1343. 
12. Reddel H, Taylor D, Bateman E.standardizing endpoints for clinical asthma trials and clinical practice. Am J RespirCrit Care Med.2009; (180):59-99 13. Tan W ,Vollmer W, LamprechtB.Worldwide patterns of bronchodilator responsiveness. Thorax 2012;(67):718-726

14. Culinan P, Lowson D, NieuwenhuijsenM.Work related symptoms in workers not previously exposed to flour. Occup Environ Med.1994;(51):579-583

15. TaliniD.BenvenutiA,CarrafaM.Diagno sis of four-induced occupational asthma in across-sectional study ./Respiratory Medicine2002; (96): 236 -243
16. Ijadunola K,.Erhabor $\quad \mathrm{G}$, OnayadeA.Prevalence of respiratory symptoms among wheat flour mill workers in Ibadan, Nigeria .American journal of Industrial Medicine.2004;( 45):3 251-259 17. NarjisA,AjeelM,AsaadK.Work related allergic disorders among Flour mills workers. The Medical journal of Basrah University.2007;(25):1-10

18. GaafarMohamed,AliMassoud,RifkiFar is,Mohamed El Sobky,MohamedShoeib . Health hazards of flour industry in Menoufia governorate.MD Thesis ,Department of Community, Environment and occupational Medicine, Faculty of Medicine, Ain Shams University. 1988;(6):72 
Table 1:Characteristics of participant workers at wheat mills of South Cairo

\begin{tabular}{|l|l|l|}
\hline \multicolumn{1}{|c|}{$\begin{array}{c}\text { Variables } \\
\mathbf{N = 1 2 0}\end{array}$} & \multicolumn{1}{|c|}{$\mathbf{N}(\boldsymbol{\%})$} & \multicolumn{1}{c|}{ Mean \pm SD [min-max] } \\
\hline Age (years) & & $49 \pm 5.6[37-59]$ \\
\hline BMI $\left(\mathrm{kg} / \mathrm{m}^{2}\right)$ & & $24.3 \pm 0.7[22.6-26.3]$ \\
\hline Smoking & & \\
\hline \multicolumn{1}{|c|}{ Non-smoker } & $46(38.3 \%)$ & \\
\hline \multicolumn{1}{|c|}{ Smoker } & $74(61.7 \%)$ & $308.8 \pm 305.7[0-1200]$ \\
\hline Smoking Index (pack/year) & & $27.4 \pm 5.1[20-40]$ \\
\hline Duration of exposure (years) & & \\
\hline Mill & & \\
\hline \multicolumn{1}{|c|}{ Sherouk } & $60(50 \%)$ & \\
\hline Tebbin & $60(50 \%)$ & \\
\hline
\end{tabular}

Table 2.Clinical findings among participant workers at wheat mills of South Cairo

\begin{tabular}{|l|r|}
\hline & $\mathbf{N}(\mathbf{\%})$ \\
\hline Recurrent RTI (duration>10days) & $34(28.3)$ \\
\hline Asthma symptoms & $31(25.8)$ \\
\hline Asthma symptoms with triggers: cold air ,irritants,laugh & $31(25.8)$ \\
\hline Episodic chest tightness & $31(25.8)$ \\
\hline Asthma symptoms during work & $30(25.0)$ \\
\hline Asthma symptoms improve at the end of work day\&weekend & $30(25.0)$ \\
\hline Episodic cough & $28(23.3)$ \\
\hline Episodic dyspnea & $27(22.5)$ \\
\hline Asthma symptoms resolve completely after awaking & $24(20.0)$ \\
\hline Chronic dyspnea & $14(11.7)$ \\
\hline Episodic wheezes & $8(6.7)$ \\
\hline Chronic productive cough & $7(5.8)$ \\
\hline Asthma symptoms resolve Partially after awaking & $6(5.0)$ \\
\hline Past history\& family history of BA & $2(1.7)$ \\
\hline Asthma symptoms leading to night awaking & $1(0.8)$ \\
\hline Abnormal chest examination & $7(8.1)$ \\
\hline Abnormal chest X ray & $7(8.1)$ \\
\hline
\end{tabular}


Table 3.The effect of the bronchodilator administration on percentage of workers with impaired spirometric parameters

\begin{tabular}{|c|c|c|c|c|c|c|}
\hline & BD intake & $\begin{array}{l}\text { Impairment } \\
\text { cutoff of } \\
\% \text { pred value }\end{array}$ & $\begin{array}{c}\text { impaired } \\
\text { total }=120\end{array}$ & $\begin{array}{c}\text { Improved } \\
\text { (increased) }\end{array}$ & $\underset{\#}{\text { Statistic }}$ & $\begin{array}{c}\mathbf{P} \\
\text {-value }\end{array}$ \\
\hline & & & $\mathrm{n}(\%)$ & n (\%) & & \\
\hline \multirow{2}{*}{$\begin{array}{l}\% \text { pred } \\
\text { FVC }\end{array}$} & Pre-BD & $<80 \%$ & $41(34.2)$ & & --- & --- \\
\hline & Post-BD & $<80 \%$ & $0(0.0)$ & 41 & & \\
\hline \multirow{2}{*}{$\begin{array}{l}\% \text { pred } \\
\text { FEV1 }\end{array}$} & Pre-BD & $<85 \%$ & 75 (62.5)\# & & 29.647 & $0.000^{*}$ \\
\hline & Post-BD & $<85 \%$ & $35(29.2)$ & 40 & & \\
\hline \multirow[t]{2}{*}{$\begin{array}{l}\% \text { FEV1 } \\
\text { /FVC }\end{array}$} & Pre-BD & $<85 \%$ & $102(85.0)$ & & 17.289 & $0.001^{*}$ \\
\hline & Post-BD & $<85 \%$ & $115(95.8)$ & 14 & & \\
\hline \multirow{2}{*}{$\begin{array}{l}\% \text { pred } \\
\text { PEFR }\end{array}$} & Pre-BD & $<80 \%$ & 67 (55.8)\#\# & & 14.604 & $0.000^{*}$ \\
\hline & Post-BD & $<80 \%$ & $16(13.3)$ & 51 & & \\
\hline
\end{tabular}

\# McNemar test

Table 4.PEFR variability among participant workers at wheat mills of South Cairo

\begin{tabular}{|l|c|c|}
\hline & $\begin{array}{c}\text { Spirometric parameters in liter } \\
\text { Mean } \pm \text { SD [min-max] }\end{array}$ & $\begin{array}{c}\text { Spirometric parameters \% pred } \\
\text { Mean } \pm \text { SD [min-max] }\end{array}$ \\
\hline PEFR & & \\
\hline Early-PEFR & $7.0 \pm 1.2[4.4-9.7]$ & $78.1 \pm 12.7[50.0-107.0]$ \\
\hline late-PEF & $5.8 \pm 2.4[0-10.83]$ & $65.3 \pm 16.5[30-118.0]$ \\
\hline Variability & & $21.0 \pm 6.8[10.0-46.0]$ \\
\hline
\end{tabular}

\#Variability: difference between percent predicted early and late PEFR 


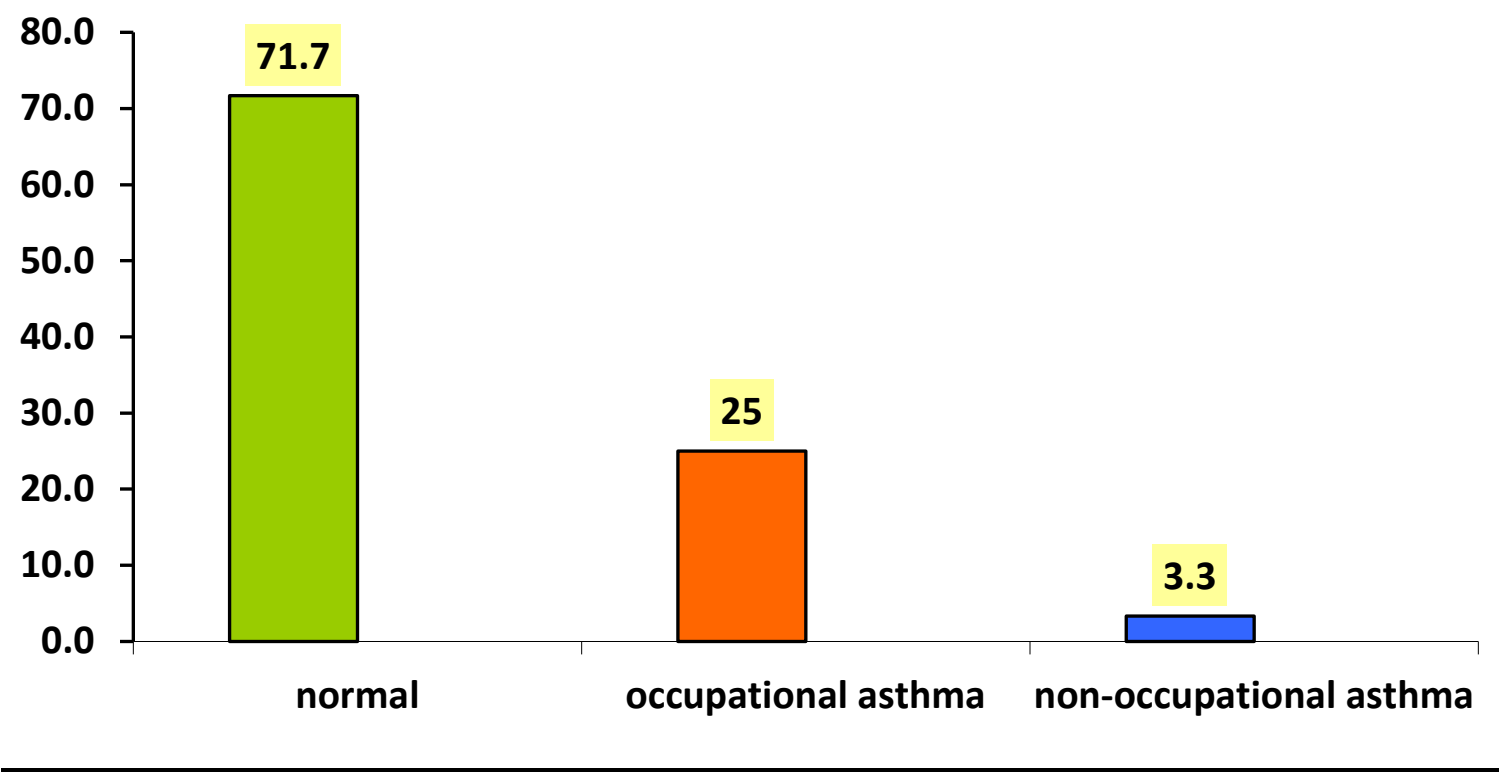

Figure 1: Percentages of occupational and non-occupational asthma in South Cairo Mills(25\% of mills workers suffer from occupational asthma) 